\title{
Chemical Composition and Biological Activities of the Essential Oils of Chrysophyllum albidum G. Don (African Star Apple)
}

\author{
Daniel Nartey $\mathbb{D}^{1,2}$ Joseph Nana Gyesi, ${ }^{1}$ and Lawrence Sheringham Borquaye $\mathbb{D}^{1,2}$ \\ ${ }^{1}$ Department of Chemistry, Kwame Nkrumah University of Science and Technology, Kumasi, Ghana \\ ${ }^{2}$ Central Laboratory, Kwame Nkrumah University of Science and Technology, Kumasi, Ghana \\ Correspondence should be addressed to Lawrence Sheringham Borquaye; lsborquaye.sci@knust.edu.gh
}

Received 7 March 2021; Accepted 1 June 2021; Published 11 June 2021

Academic Editor: Baskaran Gunasekaran

Copyright ( 2021 Daniel Nartey et al. This is an open access article distributed under the Creative Commons Attribution License, which permits unrestricted use, distribution, and reproduction in any medium, provided the original work is properly cited.

The volatile compounds of the fruit and leaf essential oils of the African star fruit, Chrysophyllum albidum G. Don, were characterized by gas chromatography-mass spectrometry in this study. The antimicrobial, antibiofilm, and antioxidant activities of the essential oils were also investigated. Thirty-five and thirty-four compounds, representing $97.84 \%$ and $97.87 \%$, were identified in the leaf and fruit essential oils, respectively. The antimicrobial activity of the oils was evaluated in vitro against eight pathogens using the broth microdilution method. The fruit essential oil exhibited broad-spectrum antimicrobial activity in the antimicrobial susceptibility test, with minimum inhibitory concentrations (MICs) ranging from 0.195 to $6.250 \mathrm{mg} / \mathrm{mL}$, while the leaf essential oils showed antimicrobial activity with MICs in the range of $6.875-13.750 \mathrm{mg} / \mathrm{mL}$. The antibiofilm activity was assessed via the crystal violet staining assay, with Pseudomonas aeruginosa as the model organism. The concentrations of the leaf and fruit essential oil required for half-maximal inhibition of biofilm formation $\left(\mathrm{BIC}_{50}\right)$ were $6.97 \pm 0.56$ and $4.78 \pm 0.21 \mathrm{mg} / \mathrm{mL}$, respectively. In evaluating antioxidant activity, the total antioxidant capacity obtained from the phosphomolybdenum assay was $104.8 \pm 2.4$ and $101.6 \pm 0.8 \mu \mathrm{g} / \mathrm{g}$ AAE for leaf and fruit essential oils, respectively. The $\mathrm{IC}_{50}$ values obtained from the hydrogen peroxide scavenging, 1,1-diphenyl-2-picrylhydrazyl (DPPH) free radical scavenging, and inhibition of lipid peroxidation assays were $301.8 \pm 0.7$ and $669.2 \pm 2.1 \mu \mathrm{g} / \mathrm{mL}, 1048.0 \pm 0.3$ and $1454.0 \pm 0.3 \mu \mathrm{g} / \mathrm{mL}$, and $460.1 \pm 2.7$ and $457.4 \pm 0.3 \mu \mathrm{g} / \mathrm{mL}$ for both leaf and fruit essential oils, respectively. The results obtained in this study suggest that the leaf and fruit essential oil of Chrysophyllum albidum G. Don could find potential use in the food, cosmetic, and pharmaceutical industries as preservative and pharmaceutical agents.

\section{Introduction}

Essential oils are common in nature and mostly represent the distinctive flavors and aromas of many plants [1]. Many herbs and spices such as garlic, black cumin, cloves, cinnamon, thyme, bay leaves, mustard, and rosemary have been reported to contain important essential oils [2]. Essential oils have been obtained from various parts of plants-fruits, leaves, roots, stem bark, seeds, etc. Plants utilize essential oils for various purposes. Some essential oils function as integral components of plant defense strategy by acting as insecticidal and antimicrobial agents. In some plants, essential oils play key roles in attracting insects for seed dispersal and flower pollination [3]. Several researches have reported essential oils as possessing a wide range of bioactivities and these activities have been attributed to the constituents of these oils. Essential oil constituents such as limonene, eugenol, pinene, carvone, and linalool have been suggested as agents responsible for the antimicrobial potency of some essential oils. Other essential components such as thymol and menthol elicit antioxidant tendencies whereas aromadendrene and $\mathrm{T}$-cadinol play a role in anti-inflammatory actions $[4,5]$.

Even though several reports of the antimicrobial activity of essential oils exist in the literature, very few studies center on the route by which these oils exert their antimicrobial action. The ability of the tea tree oil to disrupt the bacterial cytoplasmic membrane and the accompanying loss of chemiosmotic control has been suggested as the most likely source of its lethal action against Escherichia coli, 
Staphylococcus aureus, and Candida albicans [5, 6]. Other essential oil constituents, such as carvacrol and thyme, have been shown to effect their antimicrobial action by interfering with biofilm formation [7]. Biofilm formation by bacteria affords pathogenic cells the ability to escape the lethal effects of host antimicrobial molecules and systemic antibiotics. Oftentimes, this mechanism developed by pathogens results in antibiotic resistance. Biofilm inhibition or removal is therefore a potentially attractive route for eliminating bacteria [8].

Essential oils have also been explored for their antioxidant properties. Natural antioxidants are in demand due to their perceived safety profiles. Additionally, the use of synthetic antioxidants such as butylated hydroxyanisole (BHA) and butylhydroxytoluene (BHT) have been discouraged due to health, safety, and environmental concerns. As such, there is a need to find alternative antioxidants that do not carry these negative tags [9]. Lipid peroxidation, a direct consequence of the action of free radicals on fats and oils, can easily cause a deterioration in the quality of food and also decrease the nutritional value of food. Lipid peroxidation usually results in offensive flavors and odors of foods. Antioxidants could potentially contribute to the prevention and treatment of diseases caused by radicals and reactive oxygen and nitrogen species. Antioxidants could also be used in food preservation to mop up the radicals that cause lipid peroxidation [10]. Several essential oils have been shown to possess antioxidant activities. Essential oils from the leaf and fruit of Annona muricata showed interesting antioxidant capabilities [11].

Chrysophyllum albidum (Linn), commonly known as the African star apple, belongs to the family Sapotaceae which has about 800 species. It is primarily a forest tree species, and its natural occurrence has been reported in diverse ecological zones in Nigeria, Uganda, Niger Republic, Cameroon, and Cote d'Ivoire [12]. In Ghana, the tree is usually domesticated while some are found in the forest. The fruit is known as a natural source of antioxidants that can reduce free radicalmediated diseases such as diabetes, cancer, and coronary heart disease [13]. The fruits also contain $90 \%$ anacardic acid, which is used industrially in protecting wood and as a source of resin, while several other components of the tree including the roots and leaves are used as a remedy for yellow fever and malaria. The leaves are used as emollients and for the treatment of skin eruptions, diarrhea, and stomachache [14]. Several studies on Chrysophyllum albidum have focused on the nutritional content and the biological activities of the crude plant extracts $[15,16]$. Essential oils from the African star apple have only been explored to a limited extent. In 2013, Lasekan and coworkers examined the volatile constituents of the fruit pulp of the African star apple that contributed to the unique aroma and flavor of the fruit juice. Four different varieties of the fruits were used [17]. Recently, Ishola utilized hydrodistillation to extract essential oils from various parts of the plant-fruit bark, root bark, stem bark, seed bark, leaf and seed-and evaluated the antioxidant and antimicrobial capabilities of the oils [18]. As expected, different plant varieties yielded essential oils with different compositions. Since the biological activities are based on the identity and amounts of the various chemical constituents in these essential oils, the chemical composition and biological activities of the fruit pulp and leaf essential oils of Ghanaian cultivars of Chrysophyllum albidum were studied. Gas chromatography-mass spectrometry was used in identifying the chemical constituents of the essential oils. Biological activities investigated included antioxidant, antimicrobial, and antibiofilm activities.

\section{Methods}

2.1. Plant Material. Fresh fruits and leaves were sampled from Kumasi in the Ashanti region, Ghana, in February 2019. Samples were transported to the laboratory at the Department of Chemistry, Kwame Nkrumah University of Science and Technology (KNUST), Kumasi, and stored in a refrigerator at $4^{\circ} \mathrm{C}$. Plant identification and authentication were carried out at the Department of Herbal Medicine, KNUST.

2.2. Essential Oil Extraction. Fresh fruits were washed with distilled water. Afterwards, the fruit pulp was separated from the fruit bark and seeds, and then subjected to steam distillation for 4 hours in a modified Clevenger-type setup. Fresh leaves were also washed and extracted similarly. The essential oils were recovered and treated with anhydrous sodium sulfate to remove traces of water. Essential oils were stored at $4^{\circ} \mathrm{C}$ until used in further analysis. The essential oil yields were calculated with respect to the fresh weight of the plant material before distillation (expressed as percentage w/ $\mathrm{w}$ of the fresh material).

\subsection{Chemical Composition Analysis Using GC-MS.}

Chemical composition of the essential oils was assayed on a Perkin Elmer GC Clarus 580 Gas chromatograph interfaced with a Perkin Elmer (Clarus SQ 8 S) mass spectrometer. A DB-5 (ZB-5HTMS; 5\% diphenyl/95\% dimethylpolysiloxane) fused capillary column with dimensions $30 \times 0.25 \mathrm{~mm}$ ID $\times 0.25 \mu \mathrm{m}$ DF was used. The GC oven program began at $40^{\circ} \mathrm{C}$ and was held for $2 \mathrm{~min}$, followed by a gradual increase of $10^{\circ} \mathrm{C} / \mathrm{min}$ till $250^{\circ} \mathrm{C}$, then $20^{\circ} \mathrm{C} / \mathrm{min}$ to $280^{\circ} \mathrm{C}$, and a final hold for $10 \mathrm{~min}$ at $280^{\circ} \mathrm{C}$. For GC-MS detection, an electron ionization system was operated in electron impact mode. Helium gas (99.9999\%) was used as a carrier gas at a constant flow rate of $1 \mathrm{~mL} / \mathrm{min}$, and an injection volume of $1 \mu \mathrm{L}$ was employed. The injector temperature was maintained at $250^{\circ} \mathrm{C}$ and the ion-source temperature was $220^{\circ} \mathrm{C}$. Mass spectra were taken at $70 \mathrm{eV}$, a scanning interval of $1 \mathrm{~s}$, and fragments from 50 to $4500 \mathrm{Da}$. The solvent delay was from 0 to $3 \mathrm{~min}$, and the total GC/MS run time was $34.5 \mathrm{~min}$.

2.4. Compound Identification. The oil compositions were identified by matching their mass spectra data to the National Institute of Standard and Technology (NIST) and Wiley mass spectra databases, as well as mass spectra present in published data and confirmed by comparison of their relative retention indices with literature values. The 
retention indices, relative to $\mathrm{C} 9-\mathrm{C} 40 \mathrm{n}$-alkanes, were obtained on GC-MS runs with the same conditions as that of the essential oils. The retention index was calculated using

$$
\mathrm{RI}=100 n+100\left[\frac{\left(T_{\mathrm{rx}}-T_{n}\right)}{\left(T_{\mathrm{rx}}+1-T_{n}\right)}\right],
$$

where $T_{\mathrm{rx}}$ is the retention time of your target compound, $T_{n}$ is the retention time of the n-alkane before your target compound, and $T_{\mathrm{rx}+1}$ is the retention time of the $n+1$ alkane after the target peak. The quantitative composition of each peak was derived as percentages calculated by normalization of the peak area [19].

\subsection{Antimicrobial Assay}

2.5.1. Media Preparation and Microbial Strains. Microbes used included 2 Gram-positive bacteria (Staphylococcus aureus ATCC 29213, and Staphylococcus pneumoniae ATCC 49619), 5 Gram-negative bacteria (Bacillus subtilis, Salmonella typhi, Pseudomonas aeruginosa ATCC 27853, Klebsiella pneumoniae ATCC 700603, and Escherichia Coli ATCC 25922,) and a fungus (Candida albicans). Stock cultures of bacterial strains were cultivated in a nutrient broth at $37^{\circ} \mathrm{C}$ for $24 \mathrm{~h}$ before the testing. A colony suspension in sterile saline was adjusted to $0.5 \mathrm{McFarland}$ standard and further diluted in sterile double strength nutrient broth to obtain approximately $\sim 2 \times 10^{5} \mathrm{CFU} / \mathrm{mL}$.

\subsubsection{Minimum Inhibitory Concentrations (MIC)} Determination. The minimum inhibitory concentrations of the essential oils were determined in the broth dilution assay. Two-fold serial dilution of the essential oil or standard antibiotic (ciprofloxacin) was prepared in sterile 96-well microtiter plates. In each plate, $100 \mu \mathrm{L}$ of two-fold serial dilution of essential oil was transferred into the wells. To each well was added $100 \mu \mathrm{L}$ of double strength nutrient broth containing an inoculum size of $\sim 2.0 \times 10^{5} \mathrm{CFU} / \mathrm{mL}$. After incubation for 24 hours at $37^{\circ} \mathrm{C}, 20 \mu \mathrm{L}$ of $1.25 \mathrm{mg} / \mathrm{mL} 3-(4,5-$ dimethylthiazol-2-yl)-2,5-diphenyltetrazolium bromide solution (MTT) was added to each well and further incubated for $30 \mathrm{~min}$ at $37^{\circ} \mathrm{C}$. The MIC was determined as the lowest concentration of essential oil or antibiotic that completely inhibited the growth of the organism in microdilution wells as detected by the absence of the purple coloration after MTT addition during a 24-hour incubation period at $37^{\circ} \mathrm{C}$. All tests were performed in triplicate $[20,21]$.

2.6. Biofilm Inhibition. In the crystal violet staining assay, sterile microtiter plates were first filled with MIC and subMIC concentrations of essential oils and standard drug (gentamicin). Thereafter, a bacterial suspension adjusted to a turbidity of $0.5 \mathrm{McF}$ arland standard was inoculated into each well. The final volume of each well was $200 \mu \mathrm{L}$. A control experiment, in which solvent was used to replace essential oil, was also set up. The plates were incubated for 24 hours at $37^{\circ} \mathrm{C}$ and after that, the content of the wells was discarded followed by washing $3 \times$ with deionized water to remove loosely attached cells. The wells were then stained with $0.1 \%$ crystal violet followed by elution into a new plate for absorbance reading at $595 \mathrm{~nm}$. Biofilm inhibition was estimated from the following equation:

$$
\% \text { inhibition }=\frac{A_{\mathrm{c}}-A_{\mathrm{t}}}{A_{\mathrm{c}}} \times 100,
$$

where $A_{\mathrm{c}}$ is the absorbance of the control and $A_{\mathrm{t}}$ is the absorbance of the treatment groups [8].

2.7. Antioxidant Activity. The antioxidant activity of the fruit pulp and leaf essential oil of Chrysophyllum albidum was evaluated via the phosphomolybdenum, hydrogen peroxide scavenging, the 2,2-diphenyl-1-picrylhydrazyl (DPPH) radical scavenging, and inhibition of lipid peroxidation assays.

2.7.1. Phosphomolybdenum Assay. In the phosphomolybdenum (PM) assay, essential oils of different concentrations were prepared in dimethyl sulfoxide (DMSO). Five milliliters of the PM reagent $(0.6 \mathrm{M}$ sulfuric acid, $28 \mathrm{mM}$ sodium phosphate, and $4 \mathrm{mM}$ ammonium molybdate) were added to $0.5 \mathrm{~mL}$ of each test sample in a test tube, shaken, and then incubated at $95^{\circ} \mathrm{C}$ for $90 \mathrm{~min}$. After the reaction mixture had cooled to room temperature, the absorbance at $695 \mathrm{~nm}$ was read against a blank solution. Ascorbic acid was used as a standard drug in this experiment [22].

2.7.2. Hydrogen Peroxide Scavenging Assay. The effective hydrogen peroxide scavenging activity of the essential oils was assayed by adding to a test tube ferrous ammonium sulfate $(1 \mathrm{mM}, 0.5 \mathrm{~mL})$, followed by $0.13 \mathrm{~mL}$ of $5 \mathrm{mM} \mathrm{H}_{2} \mathrm{O}_{2}$ and $3 \mathrm{~mL}$ of essential oil or standard drug at varying concentrations. Each test tube was incubated in the dark for $5 \mathrm{~min}$ at room temperature. After this, 1,10-phenanthroline $(1 \mathrm{mM}, 3 \mathrm{~mL})$ was added to each mixture and the test tube was shaken to ensure uniform mixing. The reaction mixture was then incubated at room temperature for $10 \mathrm{~min}$. The absorbance of the reaction mixture was taken at $510 \mathrm{~nm}$. Water was used in place of essential oils for the blank. Gallic acid was used as a standard drug. The amount of hydrogen peroxide scavenged was obtained from the following equation:

$$
\% \text { hydrogen peroxide scavenged }=\frac{A_{\text {test }}}{A_{\text {control }}} \times 100,
$$

where $A_{\text {test }}$ is the absorbance of the test sample and $A_{\text {control }}$ is the absorbance of the blank [23].

2.7.3. DPPH Radical Scavenging Assay. The scavenging activity of 2,2-diphenyl-1-picrylhydrazyl (DPPH) free radicals of fruit pulp and leaf essential oil of Chrysophyllum albidum was performed according to the method used by Gyesi et al. [11]. Methanol was used as the negative control. L-Ascorbic acid was used as a standard drug. The percent inhibition of DPPH free radicals was 


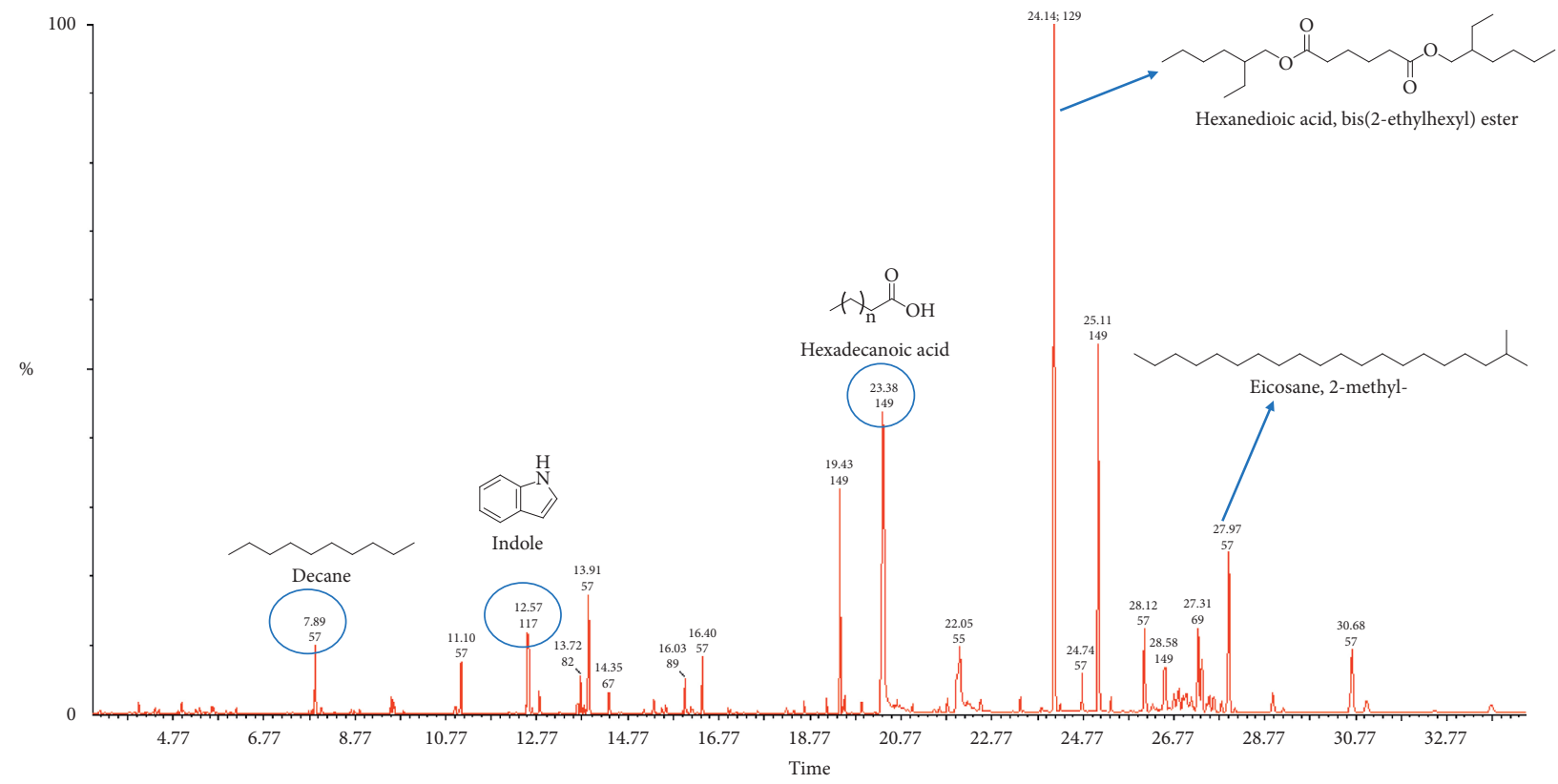

FIGURE 1: Total ion chromatogram (TIC) obtained from the GC-MS run of the essential oil from the leaves of Chrysophyllum albidum. Compounds were identified by comparison of MS spectra data with NIST and Wiley libraries as well as published literature. Chemical structures of some of the peaks are shown and were drawn with ChemDraw.

calculated from the absorbance of the control $\left(A_{\mathrm{c}}\right)$ and of the test $\left(A_{\mathrm{t}}\right)$ from the following equation:

$$
\text { inhibition }(\%)=\left[\frac{A_{\mathrm{c}}-A_{\mathrm{t}}}{A_{\mathrm{c}}}\right] \times 100 .
$$

2.7.4. Inhibition of Lipid Peroxidation (TBARS Assay). This assay was performed according to methods described by Damien Dorman et al. with slight modification [24]. Egg yolk rich in lipids was used as a source of an oxidable substrate. Briefly, $0.5 \mathrm{~mL}$ of $10 \%(\mathrm{w} / \mathrm{v}$ in $1.5 \% \mathrm{KCl})$ homogenate and $0.1 \mathrm{~mL}$ of sample solubilized in methanol were added to a test tube and made up to $1.0 \mathrm{~mL}$ with distilled water. An aliquot of $50 \mu \mathrm{L}$ of $\mathrm{FeSO}_{4}(0.07 \mathrm{M})$ was added to each sample to induce lipid peroxidation. To the mixture, $1.5 \mathrm{~mL}$ of $20 \%$ trichloroacetic acid (TCA) and $0.8 \%(\mathrm{w} / \mathrm{v})$ thiobarbituric acid (TBA) in $1.1 \%(\mathrm{w} / \mathrm{v})$ sodium dodecyl sulfate (SDS) stock reagent was added and then $1.5 \mathrm{~mL}$ of $20 \%$ acetic acid (pH adjusted to 3.5 with $\mathrm{NaOH}$ ) was added. The resulting mixture was vortexed, followed by heating at $95^{\circ} \mathrm{C}$ for $60 \mathrm{~min}$. After cooling, $5.0 \mathrm{~mL}$ of butanol was added to each tube and centrifuged at $3000 \mathrm{rpm}$ for $10 \mathrm{~min}$. The absorbance of the organic upper layer was measured at a wavelength of $532 \mathrm{~nm}$. Butylated hydroxytoluene (BHT) and ascorbic acid were used as positive controls. The percentage inhibition of lipid peroxidation was calculated from the absorbance obtained using the following equation:

$$
\% \text { inhibition } \frac{A_{\mathrm{c}}-A_{\mathrm{s}}}{A_{\mathrm{c}}} \times 100
$$

where $A_{\mathrm{c}}$ is the absorbance of blank and $A_{\mathrm{s}}$ is the absorbance of the sample mixture.
The $\mathrm{IC}_{50}$ values (extract concentration needed to achieve $50 \%$ inhibition of lipid peroxidation) were obtained from a graph of \% inhibition against concentration.

2.8. Data Analysis. All experiments were conducted in triplicates and data presented as mean \pm standard deviation. Statistical analyses were performed in GraphPad Prism 6.0 for Windows (GraphPad Software, San Diego, CA, USA). $p<0.05$ was considered to be statistically significant.

\section{Results}

Steam distillation was used in isolating essential oils from fruits and leaves of Chrysophyllum albidum in yields of $0.53 \%$ and $0.17 \%$, respectively. Both essential oils were pale yellow in color. Figures 1 (leaf) and 2 (fruit) represent the total ion chromatograms obtained from the GC-MS analysis. Compounds were identified by comparing the mass spectra obtained in the GC-MS run with available NIST and Wiley spectra libraries. Confirmation of identified constituents was done by comparing the computed linear retention index of each compound to corresponding indices in literature and available web-based sources $[19,25]$. A total of 35 compounds were identified in the leaf essential oil and this represented $97.84 \%$ of the total oil constituents. For the fruit essential oil, 34 compounds which represent $97.86 \%$ of the total oil constituents were identified. Tables 1 and 2 show the chemical composition of the fruit and leaf essential oils. The leaf essential oil was made up of compounds classified as alkanes ( 28.49\%), carboxylic acids $(\sim 28.38 \%)$ esters ( 27.87\%), and terpenes/terpenoids ( 5.55\%). The fruit essential oil also had alkanes ( 26.90\%), esters $(\sim 26.29 \%)$, 


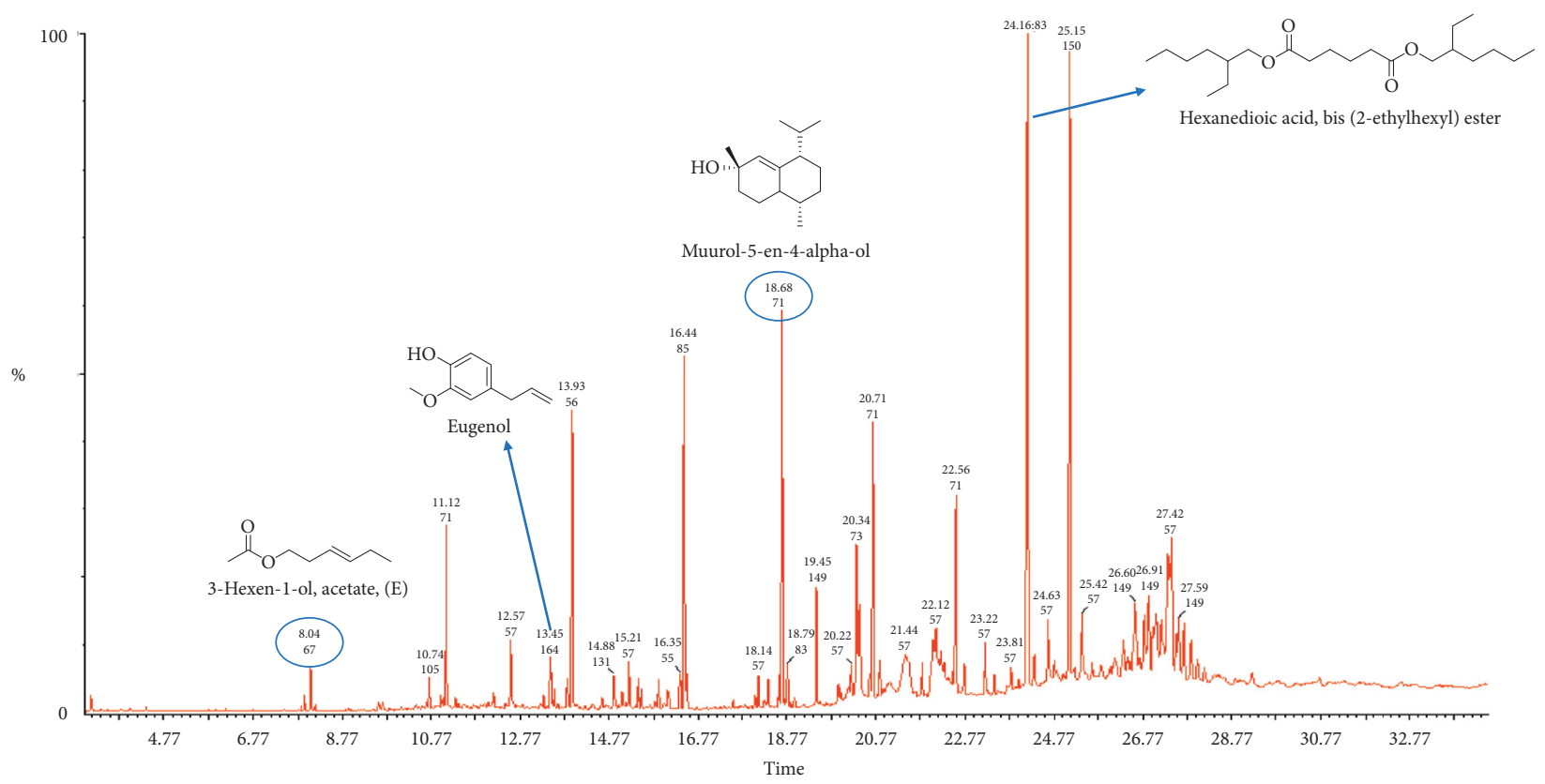

FIgURE 2: Total ion chromatogram (TIC) obtained from the GC-MS run of the essential oil from the fruits of Chrysophyllum albidum. Compounds were identified by comparison of MS spectra data with NIST and Wiley libraries as well as published literature. Chemical structures of some of the peaks are shown and were drawn with ChemDraw.

and terpenes/terpenoids $(\sim 24.25 \%)$ as the most abundant constituents (Table 3).

The essential oils from the fruit and leaf of Chrysophyllum albidum were screened against 8 bacteria and 1 fungus. The results of the antimicrobial susceptibility test are represented in Table 4. The MICs of the leaf essential oil against all tested microorganisms ranged between 6.875 and $13.750 \mathrm{mg} / \mathrm{mL}$, whereas those of the fruit essential oils were between 0.195 and $6.250 \mathrm{mg} / \mathrm{mL}$. In general, the fruit essential oil exhibited better antimicrobial activity when compared to the leaf essential oil. Bacillus subtilis, Salmonella typhi, and Pseudomonas aeruginosa were the most susceptible organisms to the fruit essential oil with MICs less than $2 \mathrm{mg} / \mathrm{mL}$, whereas Candida albicans, Staphylococcus aureus, and Pseudomonas aeruginosa were the most susceptible organisms to the leaf essential oil. Both essential oils displayed medium antimicrobial activity towards Candida albicans, which was the only fungus used in this study.

In the biofilm inhibitory assays, the fruit and leaf essential oils were screened against Pseudomonas aeruginosa biofilms. Essential oils were evaluated at MIC and sub-MICs (Table 5). Interestingly for both extracts, there was over 50\% biofilm inhibition at all concentrations tested. For both extracts, a maximum inhibitory effect of over $70 \%$ was recorded. The maximum biofilm inhibitory effect of the positive control, gentamicin, was $88.42 \%$ at its MIC. In general, there was a dose-dependent relationship in biofilm inhibition for all treatments. The concentration of leaf essential oil required to elicit half-maximal inhibition of biofilm formation $\left(\mathrm{BIC}_{50}\right)$ was significantly different $(p<0.05)$ from that of the fruit essential oil. The fruit essential was much better at inhibiting biofilm formation $\left(\mathrm{BIC}_{50}\right.$ of $\left.4.78 \pm 0.21 \mathrm{mg} / \mathrm{mL}\right)$ than the leaf essential oil
$\left(\mathrm{BIC}_{50}\right.$ of $\left.6.97 \pm 0.56 \mathrm{mg} / \mathrm{mL}\right)$. Gentamicin was, however, superior to both leaf and fruit essential oils with a $\mathrm{BIC}_{50}$ of $1.62 \pm 0.28 \mu \mathrm{g} / \mathrm{mL}$.

In the phosphomolybdenum assay, the total antioxidant capacity for the leaf and fruit essential oils was determined to be $104.76 \pm 2.4$ and $101.59 \pm 0.83 \mu \mathrm{g} / \mathrm{g}$ AAE, respectively. There was no significant difference $(p<0.05)$ in the TAC of the two essential oils. The $\mathrm{IC}_{50}$ values obtained in the hydrogen peroxide scavenging test were $1048 \pm 0.27$ and $1454 \pm 0.26 \mu \mathrm{g} / \mathrm{mL}$ for the leaf and fruit essential oil, respectively. Gallic acid was used as the standard in the hydrogen peroxide scavenging test. Comparatively ascorbic acid performed better than both the leaf and fruit essential oils with an $\mathrm{IC}_{50}$ value of $87.51 \pm 0.37 \mu \mathrm{g} / \mathrm{mL}$. Based on the recorded $\mathrm{IC}_{50}$ values, the leaf essential oil was about $50 \%$ better at scavenging hydrogen peroxide when compared to the fruit essential oil. Both oils though can be described as possessing only moderate activity in this assay. The $\mathrm{IC}_{50}$ values for the leaf and fruit essential oils in the DPPH assay were $301.8 \pm 0.7$ and $669.2 \pm 2.12 \mu \mathrm{g} / \mathrm{mL}$, respectively. Ascorbic acid, with an $\mathrm{IC}_{50}$ of $11.94 \pm 1.9 \mu \mathrm{g} / \mathrm{mL}$, was used as a standard drug. A dose-dependent scavenging of the DPPH radical was observed for all test and standard drugs. The leaf and fruit pulp essential oil showed good activities in the inhibition of lipid peroxidation test. The concentrations at which $50 \%$ of lipid peroxidation was inhibited were determined to be $460.1 \pm 2.7$ and $457.4 \pm 0.3 \mu \mathrm{g} / \mathrm{mL}$ for the leaf and fruit essential oils. The $\mathrm{IC}_{50}$ value for butylated hydroxytoluene (BHT), a standard drug, was $8.0 \pm 0.4 \mu \mathrm{g} / \mathrm{mL}$. Table 6 summarizes the results for the antioxidant activities of the leaf and fruit pulp essential oil of Chrysophyllum albidum. 
TABLE 1: Chemical composition of the leaf essential oil of Chrysophyllum albidum as determined by GC-MS.

\begin{tabular}{|c|c|c|c|c|}
\hline $\mathrm{S} / \mathrm{N}$ & Compound name & $\% \mathrm{C}$ & $\mathrm{RI}^{\mathrm{a}}$ & $\mathrm{RI}^{\mathrm{b}}$ \\
\hline 1 & 1,3-Dimethylcyclohexane cis-trans & 0.375 & 740 & ${ }^{*}$ ni \\
\hline 2 & Ethylcyclohexane & 0.473 & 810 & ${ }^{*}$ ni \\
\hline 3 & 4,6-Octadiyn-3-one, 2-methyl- & 0.434 & 846 & ${ }^{*}$ ni \\
\hline 4 & Decane & 1.720 & 972 & 1000 \\
\hline 5 & Linalyl anthranilate & 0.894 & 1071 & ${ }^{*}$ ni \\
\hline 6 & Undecane & 2.097 & 1166 & 1100 \\
\hline 7 & Indole & 3.419 & 1363 & 1301 \\
\hline 8 & Ethanone, 1-(2-hydroxy-5-methylphenyl)- & 0.558 & 1381 & 1316 \\
\hline 9 & cis-Hexanoic acid & 0.415 & 1341 & ${ }^{*}$ ni \\
\hline 10 & 2,7-Octadiene, 4-methyl- & 1.051 & 1345 & ${ }^{*}$ ni \\
\hline 11 & Tetradecane & 3.460 & 1358 & ${ }^{*}$ ni \\
\hline 12 & 1,5-Cyclooctadiene, 1,3-dimethyl- & 0.745 & 1390 & ${ }^{*} \mathrm{ni}$ \\
\hline 13 & $(\mathrm{Z}, \mathrm{E})-\alpha$-farnesene & 0.556 & 1465 & 1488 \\
\hline 14 & 3,7,11-Trimethyl-3-hydroxy-6,10-dodecadien-1-yl acetate & 1.377 & 1520 & ${ }^{*}$ ni \\
\hline 15 & 3-Hexen-1-ol, benzoate, $(\mathrm{Z})$ - & 0.388 & 1529 & 1569 \\
\hline 16 & Hexadecane & 1.555 & 1550 & 1600 \\
\hline 17 & Sulfurous acid, 2-ethylhexyl hexyl ester & 0.380 & 1740 & *ni \\
\hline 18 & Hexahydrofarnesyl acetone & 0.416 & 1786 & 1801 \\
\hline 19 & Farnesyl acetate $<(\mathrm{Z}, \mathrm{E})->$ & 6.210 & 1813 & 1818 \\
\hline 20 & 4-Benzyloxybenzoic acid & 0.644 & 1823 & ${ }^{*}$ ni \\
\hline 21 & n-Hexadecanoic acid & 20.245 & 1903 & 1942 \\
\hline 22 & 1-(Hydroxymethyl)-1-(2'-hydroxyethyl) cyclopropane & 0.388 & 1927 & ${ }^{*}$ ni \\
\hline 23 & 2,7-Dimethyloctane & 1.634 & 1932 & ${ }^{*} \mathrm{ni}$ \\
\hline 24 & Phytol & 0.574 & 2046 & 2096 \\
\hline 25 & Alkynyl stearic acid & 6.905 & 2073 & ${ }^{*}$ ni \\
\hline 26 & Undecanoic acid & 1.230 & 2092 & ${ }^{*}$ ni \\
\hline 27 & Hexadecane & 0.396 & 2124 & ${ }^{*}$ ni \\
\hline 28 & 2-Bromotetradecane & 0.473 & 2218 & ${ }^{*}$ ni \\
\hline 39 & Hexanedioic acid, bis(2-ethylhexyl) ester & 19.100 & 2307 & ${ }^{*}$ ni \\
\hline 30 & Tridecanol, 2-ethyl-2-methyl- & 1.081 & 2391 & ${ }^{*}$ ni \\
\hline 31 & 2-Bromononane & 0.461 & 2494 & ${ }^{*}$ ni \\
\hline 32 & 1-Iodo-2-methylundecane & 4.077 & 2632 & ${ }^{*}$ ni \\
\hline 33 & Squalene & 4.097 & 2193 & ni \\
\hline 34 & Eicosane, 2-methyl- & 7.876 & 2275 & ni \\
\hline 35 & 2-methyloctacosane & 4.289 & 2386 & 2388 \\
\hline
\end{tabular}

$\mathrm{S} / \mathrm{N}$ : compound number in order of elution; \%C-\% composition of compound in essential oil; $\mathrm{RI}^{\mathrm{a}}$ : retention index calculated from retention times relative to C8-C40 n-alkanes on a DB-5 column; RI ${ }^{\text {b }}$ retention index from literature and web-based sources [19, 25]; *ni-not identified (compounds do not have their retention index reported for a DB-5 column in literature; compound identified from the NIST or Wiley database by comparing mass spectra with spectral similarity score of 70 and above.

\section{Discussion}

Many plant metabolites have served as lead compounds in the discovery of drugs [26]. Essential oils, so-called, because they represent the essence of plants, are mostly obtained by steam distillation, hydrodistillation, and cold pressing of various plant parts. Essential oils have been shown to possess broad-spectrum biological effects and hence they have been investigated for these purposes. Essential oils are mostly present in trace amounts in plant epidermic cells, secretory cells, canals, and cavities. The diverse compounds present in essential oils contribute to the aroma of the oil [27]. The major compound present in an essential oil may range from 20 to $85 \%$. These major constituents may contribute greatly to the aroma and biological activity of the essential oil. Compounds present in trace amounts may also act in synergy to elicit specific biological effects [28]. The low amounts of essential oils secreted by plants result in the low yield of these oils after extraction. Mostly, the yield of essential oils reported is less than 1\% [28] and the yields obtained from the leaf and fruits $(0.17 \%$ and $0.53 \%$, resp.) of Chrysophyllum albidum follow this trend.

To identify the chemical constituents of essential oils, GC-MS is normally employed. Characterization of essential oil constituents could serve as a fingerprint for that plant and also help in identifying the chemical constituents that may be responsible for any observed biological activities. The essential oil of the leaf was dominated by hydrocarbons, carboxylic acids, and terpenes. n-Hexadecanoic acid was the major compound present in the leaf essential oil and constituted $20.25 \%$ of the total oil composition. The nature of this major component, which is a fatty acid, suggests it may act as an antioxidant [29]. A previous study by Ishola identified the sesquiterpene, $\alpha$-farnesene $(38.11 \%)$, as the major compound present in the leaf essential oil [18]. In this study, $\alpha$-farnesene represented only $0.56 \%$ of the total leaf essential oil composition. The fruit pulp essential oil was dominated by terpenoids, hydrocarbons, and esters. 
TABLE 2: Fruit essential oil composition of Chrysophyllum albidum as determined by GC-MS.

\begin{tabular}{|c|c|c|c|c|}
\hline $\mathrm{S} / \mathrm{N}$ & Compound name & $\% \mathrm{C}$ & $\mathrm{RI}^{\mathrm{a}}$ & $\mathrm{RI}^{\mathrm{b}}$ \\
\hline 1 & 3-Hexen-1-ol, acetate, (E) & 0.886 & 980 & 1018 \\
\hline 2 & Benzoic acid, ethyl ester & 1.043 & 1142 & 1165 \\
\hline 3 & Cyclododecane & 0.524 & 1159 & ${ }^{*}$ ni \\
\hline 4 & Dodecane & 4.151 & 1167 & ${ }^{*}$ ni \\
\hline 5 & Tridecane, 7-methy & 0.511 & 1337 & *ni \\
\hline 6 & Eugenol & 1.824 & 1325 & 1352 \\
\hline 7 & 7-Hexadecene, (Z) & 0.873 & 1300 & *ni \\
\hline 8 & Tetradecane & 8.314 & 1359 & ${ }^{*}$ ni \\
\hline 9 & 2-Propenoic acid, 3-phenyl-, ethyl ester & 1.029 & 1429 & 1462 \\
\hline 10 & 1-Cyclohexene, 1,3,3-trimethyl-2-(1-methylbut-1-en-3-on-1-yl & 0.822 & 1471 & ${ }^{*}$ ni \\
\hline 11 & 1,1,4,5,6-pentamethyl-2,3-dihydro-1H-indene & 0.444 & 1477 & $*$ ni \\
\hline 12 & Pentadecane, 3-methyl & 0.561 & 1523 & ${ }^{*}$ ni \\
\hline 13 & 1-Hexadecanol & 0.909 & 1545 & 1873 \\
\hline 14 & Muurol-5-en-4-alpha-ol & 11.478 & 1553 & 1554 \\
\hline 15 & Davanone-2-ol & 0.640 & 1717 & 1717 \\
\hline 16 & Sinensal & 10.140 & 1745 & 1751 \\
\hline 17 & Eicosane & 8.263 & 1851 & *ni \\
\hline 18 & n-Hexadecanoic acid & 4.256 & 1936 & 1961 \\
\hline 19 & Manool (epi-13) & 1.089 & 1951 & 1958 \\
\hline 20 & Methyl 3,5-dicyclohexyl-4-hydroxybenzoate & 1.422 & 1975 & *ni \\
\hline 21 & 1,4-Epoxynaphthalene-1(2H)-methanol,4,5,7-tris(1,1 dimethylethyl)-3,4-dihydro & 6.083 & 2010 & ${ }^{*}$ ni \\
\hline 22 & Phytol & 0.916 & 2048 & 2096 \\
\hline 23 & 11,14-Eicosadienoic acid, methyl ester & 3.362 & 2073 & ${ }^{*}$ ni \\
\hline 24 & Stearic acid & 1.687 & 2092 & 2169 \\
\hline 25 & Heneicosane, 3-methyl & 1.813 & 2100 & ${ }^{*}$ ni \\
\hline 26 & 9-Tricosene, $(\mathrm{Z}$ & 1.367 & 2191 & ${ }^{*}$ ni \\
\hline 27 & Hexanedioic acid, bis(2-ethylhexyl) ester & 16.264 & 2309 & ${ }^{*}$ ni \\
\hline 28 & Octadecane, 3-ethyl-5-(2-ethylbutyl & 0.526 & 2404 & ${ }^{*}$ ni \\
\hline 39 & à-Amyrin & 0.812 & 2579 & ${ }^{*}$ ni \\
\hline 30 & Oleyl palmitoleate & 1.085 & 3360 & ${ }^{*}$ ni \\
\hline 31 & 1,2-Propanediol, 3-(octadecyloxy)-, diacetate & 0.504 & 3446 & ${ }^{*}$ ni \\
\hline 32 & Oleic acid, 3-(octadecyloxy)propyl ester & 0.902 & 3507 & ${ }^{*}$ ni \\
\hline 33 & tri(2-Ethylhexyl) trimellitate & 1.904 & 3539 & ${ }^{*}$ ni \\
\hline 34 & 7,8-Epoxylanostan-11-ol, 3-acetoxy & 1.115 & 3577 & ${ }^{*}$ ni \\
\hline
\end{tabular}

$\mathrm{S} / \mathrm{N}$ : compound number in order of elution; \%C-\% composition of compound in essential oil; $\mathrm{RI}^{\mathrm{a}}$ : retention index calculated from retention times relative to C8-C40 n-alkanes on a DB-5 column; RI : retention index from literature and web-based sources [19, 25]; ni: not identified (compounds do not have their retention index reported for a DB-5 column in literature); compound identified from the NIST or Wiley database by comparing mass spectra with spectral similarity score of 70 and above.

TABLE 3: Classification of compounds identified in both leaf and fruit essential oils of Chrysophyllum albidum.

\begin{tabular}{lcc}
\hline Compound class & Leaf essential oil (\% composition) & Fruit essential oil (\% composition) \\
\hline Alcohols & 1.08 & 2.97 \\
Alkanes & 28.49 & 26.90 \\
Carboxylic acids & 28.38 & 7.03 \\
Esters & 27.87 & 26.29 \\
Ketones & 0.97 & 1.03 \\
Sterols & 0.57 & 0.92 \\
Terpenes/terpenoids & 5.54 & 24.25 \\
\#Others & 4.92 & 8.46 \\
Total & 97.84 & 97.86 \\
\hline
\end{tabular}

"Others include compound classes such as aromatic hydrocarbons, coumarins, amines, and phenols.

Hexanedioic acid, bis(2-ethylhexyl) (16.26\%), was the major compound present in the fruit pulp essential oil. Lasekan and coworkers utilized a headspace solid-phase microextraction and GC-MS to determine the volatile constituents of the pulp of the fruit in attempt to identify compounds which contribute to the aroma of fruit juice made from the
African star apple. Esters (such as ethyl dodecanoate, methylhexanoate, ethyl hexanoate, and hexyl butanoate) and terpenoids (such as $\alpha$ - and $\beta$-pinene, geraniol, and $\alpha$-muurolene) were the major contributors to the aroma of the fruit juice [17]. Esters in essential oils are usually the products of the esterification of alcohols and acyl-CoAs 
TABLE 4: Antimicrobial activity: minimum inhibitory concentrations of fruit and leaf essential oils of Chrysophyllum albidum against various pathogenic microorganisms.

\begin{tabular}{lccc}
\hline Microorganism (Gram status) & & Minimum inhibitory concentrations $(\mathrm{mg} / \mathrm{mL})$ & Fruit essential oil \\
\hline S. aureus (+) & Leaf essential oil & 6.250 & ${ }^{*}$ Ciprofloxacin \\
S. pneumoniae (+) & 6.875 & 6.250 & 3.563 \\
B. subtilis (-) & 13.750 & 0.195 & 3.125 \\
S. typhi (-) & 13.750 & 0.783 & 1.563 \\
P. aeruginosa (-) & 13.750 & 1.563 & 1.563 \\
E. coli (-) & 6.875 & 6.250 & 3.125 \\
K. pneumoniae (-) & 13.750 & 6.250 & 1.563 \\
\# C. albicans & 13.750 & 6.250 & 1.563 \\
\hline
\end{tabular}

${ }^{*}$ MICs of ciprofloxacin are in $\mu \mathrm{g} / \mathrm{ml} ;+$, Gram-positive bacteria; -, Gram-negative bacteria; ${ }^{*} \mathrm{C}$. albicans is a fungus.

TABLE 5: Inhibition of P. aeruginosa biofilm formation by of leaf and fruit essential oils of Chrysophyllum albidum.

\begin{tabular}{lccc}
\hline${ }^{*}$ Concentrations & Leaf essential oil & $\begin{array}{c}\text { \% biofilm inhibition } \\
\text { Fruit essential oil }\end{array}$ & ${ }^{* G e n t a m i c i n ~}$ \\
\hline MIC & $72.96 \pm 0.7$ & $72.4 \pm 1.2$ & $88.42 \pm 0.86$ \\
MIC/2 & $69.04 \pm 0.9$ & $55.39 \pm 2.4$ & $65.00 \pm 1.21$ \\
MIC/4 & $68.76 \pm 0.3$ & $55.82 \pm 2.3$ & $57.07 \pm 1.67$ \\
MIC/8 & $67.07 \pm 0.9$ & $55.18 \pm 0.2$ & $56.43 \pm 1.34$ \\
MIC/16 & $65.13 \pm 2.7$ & $51.57 \pm 0.4$ & $48.91 \pm 0.89$ \\
MIC/32 & $64.47 \pm 0.4$ & $50.60 \pm 0.9$ & $45.50 \pm 1.10$ \\
${ }^{* *}$ BIC $_{50}(\mathrm{mg} / \mathrm{mL})$ & ${ }^{* *} 6.97 \pm 0.56^{\mathrm{a}}$ & ${ }^{* *} 4.78 \pm 0.21^{\mathrm{b}}$ & $* 0.00162 \pm 0.28^{\mathrm{c}}$ \\
\hline
\end{tabular}

Data presented as mean \pm standard deviation, $n=3$; " concentrations of essential oils or gentamicin used were based on their minimum inhibitory concentration (MIC) against P. aeruginosa; * gentamicin was used for comparison purposes. ${ }^{* *} \mathrm{BIC}_{50}$ values computed from dose-response curve. Different superscript letters $(\stackrel{\mathrm{a}, \mathrm{b}, \mathrm{c}}{)})$ indicate significant difference in $\mathrm{BIC}_{50}$ values $(p<0.05)$.

TABle 6: Antioxidant activities of leaf and fruit essential oils of Chrysophyllum albidum as determined from different assays.

\begin{tabular}{|c|c|c|c|c|}
\hline Sample & $\begin{array}{l}\text { Total antioxidant capacity } \\
(\mu \mathrm{g} / \mathrm{g} \text { AAE })\end{array}$ & $\begin{array}{l}\text { DPPH radical scavenging } \\
\text { activity } \mathrm{IC}_{50}(\mu \mathrm{g} / \mathrm{mL})\end{array}$ & $\begin{array}{c}\mathrm{H}_{2} \mathrm{O}_{2} \text { scavenging activity } \\
\mathrm{IC}_{50}(\mu \mathrm{g} / \mathrm{mL})\end{array}$ & $\begin{array}{c}{ }^{* *} \text { TBARS IC }_{50} \\
(\mu \mathrm{g} / \mathrm{mL})\end{array}$ \\
\hline Leaf & $104.8 \pm 2.4$ & $301.8 \pm 0.7$ & $1048.0 \pm 0.3$ & $460.1 \pm 2.7$ \\
\hline Fruit & $101.6 \pm 0.8$ & $669.2 \pm 2.1$ & $1454.0 \pm 0.3$ & $457.4 \pm 0.3$ \\
\hline Ascorbic acid & nd & $11.9 \pm 1.9$ & nd & $6.7 \pm 0.3$ \\
\hline $\begin{array}{l}\text { Butylated Hydroxytoluene } \\
\text { (BHT) }\end{array}$ & nd & nd & nd & $8.0 \pm 0.4$ \\
\hline Gallic acid & nd & nd & $87.5 \pm 0.4$ & nd \\
\hline
\end{tabular}

Data represented as mean \pm standard deviation, $n=3$; ${ }^{*}$ TAC: total antioxidant capacity; ${ }^{* *}$ TBARS: thiobarbituric acid reactive substance assay; nd: not determined (compound not used in that experiment).

derived from both amino acid and fatty acid metabolisms in the plant [30]. In Ishola's study, essential oils from the fruit bark of the Chrysophyllum albidum plant was also studied [18]. Not surprisingly, some compounds present in the essential oil from the pulp were also identified in the fruit bark essential oil. One such common compound is à-amyrin. In general, the differences in the chemical constituents of the leaf and fruit essential oil analyzed in this study and those of other previous works may be attributed to geographical variations, stage of fruit or leaf maturity, nutritional condition of the plant, as well as chemotypic variations in the plants used [31,32].

Essential oils have gained much interest in the food industry due to their potential applications as natural food preservatives against food spoilage microbes [33]. The fruit and leaf essential oils exhibited broad-spectrum antimicrobial activity against all tested pathogens. Overall, the fruit essential oil exhibited better antimicrobial activity as compared to the leaf essential oil (Table 4). The fruit essential oil showed better activity against Bacillus subtilis, Salmonella typhi, and Pseudomonas aeruginosa. Ishola and team had earlier shown that some strains of Escherichia coli, Bacillus subtilis, Salmonella typhi, and Pseudomonas aeruginosa were resistant to the leaf essential oil but Staphylococcus aureus was susceptible. A different trend was observed in this study, where the leaf essential oil demonstrated broad-spectrum antimicrobial activity against Escherichia Coli, Bacillus subtilis, Salmonella typhi, and Pseudomonas aeruginosa. The differences in the antimicrobial activity of the leaf essential oil in this study and that of the Nigerian study may be as a 
result of differences in chemical compositions of the leaf essential oils in the 2 studies. The leaf essential oil in this study contains essential components such as linalyl anthranilate, which might be responsible for the observed antimicrobial activity. This compound was absent in the study by Ishola and team. Linalyl anthranilate has been proposed to react with bacteria cell membrane components to produce reactive oxygen species (ROS). These ROS could initiate lipid oxidation via a membrane lipid attack and could thus disrupt bacterial cell membrane and hence leak intracellular contents. The ROS could also leak into intracellular regions and degrade nucleic acids, lipids, and/or proteins [34]. The presence of sesquiterpenes may also contribute to the antimicrobial activity of essential oils. Sesquiterpenes, due to their inherent lipophilicity properties, could enhance an intracellular accumulation of DNA, and thus impermeabilizing the cytoplasmic membrane of Lactobacillus fermentum. This suggests that the increased permeability will potentiate the rupture of the cytoplasmic membrane [35]. In both fruit pulp and leaf essential oils, the sesquiterpenes, à-amyrin, and $(\mathrm{Z}, \mathrm{E})$ - $\alpha$-farnesene were present, respectively (Tables 1 and 2). These molecules may as well contribute to the antimicrobial activity of the essential oils.

Pseudomonas aeruginosa is a biofilm-forming organism [8]; hence the activity of the oils against this organism prompted us to investigate the biofilm inhibition potential of the fruit and leaf essential oil of Chrysophyllum albi$d u m$. Both fruit and leaf essential oil exhibited very good inhibitory properties, with percentage inhibition above $50 \%$ at all concentrations tested (Table 5). The fruit essential oil demonstrated good antibiofilm activity with a $\mathrm{BIC}_{50}$ value of $698.80 \mu \mathrm{g} / \mathrm{mL}$ as opposed to the leaf essential oil with a $\mathrm{BIC}_{50}$ value of $477.9 \mu \mathrm{g} / \mathrm{mL}$. Biofilm formation usually occur in 4 phases: initial surface attachment of bacteria cells, microcolony formation through assembly of the bacteria cells, biofilm maturation, and, finally, biofilm dispersal. Abolishing the initial attachment of planktonic cells to surfaces has been suggested as a promising route for antibiofilm activity [36]. Essential oil constituents such as eugenol and the amyrins have been shown to disrupt initial attachment of bacteria cells to various surfaces and thus interfere with biofilm formation [37, 38]. The presence of these compounds in both essential oils investigated in this work may suggest a similar mode of antibiofilm action. Essential oils could interfere with quorum sensing factors produced by Gramnegative and Gram-positive bacteria. Quorum sensing mediates virulence factors production, swarming motility, and biofilm formation in many bacteria [8]. Thus, interrupting the action of quorum sensing factors could also lead to antibiofilm action. Terpenoids such as eugenol and geraniol have been shown to also possess anti-quorum sensing properties and thus inhibit biofilm formation via this route [39].

Oxidation is a relevant biochemical process, but complete oxidation is very detrimental to the health status of living organism because it can cause damage to cell components, including DNA, lipids, and proteins [40].
Scavenging and subsequent neutralization of species which can promote excessive oxidation is thus important. The essential oils demonstrated free radical scavenging activity in the DPPH and $\mathrm{H}_{2} \mathrm{O}_{2}$ assays. For the $\mathrm{DPPH}$ radical scavenging assay, the leaf and fruit pulp essential oils were able to scavenge $50 \%$ of free radical at concentrations of $301.8 \pm 0.68$ and $669.2 \pm 2.12 \mu \mathrm{g} / \mathrm{mL}$. Comparatively, the leaf essential oil acted as better hydrogen donating or radical scavenging activity in the DPPH assay. In the hydrogen peroxide assay, the leaf essential oil performed superiorly with an $\mathrm{IC}_{50}$ value of $1048 \pm 0.27 \mu \mathrm{g} / \mathrm{mL}$ as compared to the fruit pulp essential oil with an $\mathrm{IC}_{50}$ value of $1454 \pm 0.26 \mu \mathrm{g} / \mathrm{mL}$. Sterols and esters contribute to the antioxidant activities of fruit essential oil. Gyesi and team investigated the chemical composition and antioxidant activity of the fruit pulp essential oil of Annona muricata. The fruit pulp essential oil of Annona muricata reveals esters and sterols as major compounds present in the oil. Fatty acids, sterols, and esters are known to contribute to antioxidant activity [11]; hence the high content of esters and fatty acids in the fruit pulp and leaf essential oils may have contributed to the antioxidant activity in the present study. Also, the presence of compounds such as eugenol, muurol-5-en-4-alpha-ol, davanone-2-ol, and phytol in the fruit pulp essential oil may contribute to the antioxidant activity. The total antioxidant capacities for both fruit pulp and leaf essential oils were almost similar. To scavenge ROS, the antioxidant agent could interfere with the initiation or chain propagation steps involved in free radicalmediated oxidation. The antioxidant agent could also induce processes that lead to the production of antioxidant enzymes [41]. Lipid peroxidation leads to spoilage of lipidrich foods. Inhibition of lipid peroxidation in foods is thus very desirable in potential food additives. The low $\mathrm{IC}_{50}$ of the leaf and fruit pulp essential oils in the inhibition of lipid peroxidation assays is an indication that these oils could be harnessed as preservatives. In recent times, the use of synthetic antioxidants such as BHT and BHA has been met with a negative perception of consumers, hence the need for safe and naturally derived antioxidants that can be applied in the food industry [33]. The fruit and leaf essential oils of Chrysophyllum albidum have shown good antioxidant activities in a variety of assays and could potentially have a variety of applications in the food industry.

\section{Conclusion}

The study evaluated the chemical composition and some biological properties of the fruit and leaf essential oils of Chrysophyllum albidum. Thirty-five compounds were identified in the leaf essential oil, with n-hexadecanoic acid as the most abundant compound. In the fruit essential oil, 34 compounds were identified. The oils demonstrated broadspectrum antimicrobial activity against some pathogenic microorganisms and impressive biofilm inhibition properties against Pseudomonas aeruginosa. All oils also showed very good antioxidant potential and inhibited lipid peroxidation. Based on the antioxidant and antimicrobial activities of the fruit and leaf essential oil of Chrysophyllum 
albidum, the oils could have potential applications as food preservatives.

\section{Data Availability}

All the data generated or analyzed during this study are included in this published article.

\section{Conflicts of Interest}

All the authors declare no competing financial, professional, or personal interests that might have influenced the performance or presentation of the work described in this manuscript.

\section{Authors' Contributions}

L. S. Borquaye and D. Nartey conceived the study. All the experiments were designed by L. S. Borquaye, J. N. Gyesi , and D. Nartey. D. Nartey and J. N. Gyesi carried out the experiments and analyzed the data. All the authors read and approved the final manuscript.

\section{Acknowledgments}

The Department of Chemistry and the KNUST Central Laboratory are acknowledged for the use of their facilities for this study. The authors are grateful to Mrs. Rita Opoku of the Central Laboratory, KNUST, for the technical support. The authors received no direct funding for this research.

\section{References}

[1] M. Simões, M. Lemos, and L. C. Simões, "Phytochemicals against drug-resistant microbes," in Dietary Phytochemicals and Microbes, pp. 185-205, Springer, Dordrecht, Netherlands, 2012.

[2] S. Baptista-Silva, S. Borges, O. L. Ramos, M. Pintado, and B. Sarmento, "The progress of essential oils as potential therapeutic agents: a review," Journal of Essential Oil Research, vol. 32, no. 4, pp. 279-295, 2020.

[3] P. Rubiolo, B. Sgorbini, E. Liberto, C. Cordero, and C. Bicchi, "Essential oils and volatiles: sample preparation and analysis. A review," Flavour and Fragrance Journal, vol. 25, no. 5, pp. 282-290, 2010.

[4] K. Bazaka, M. V. Jacob, W. Chrzanowski, and K. Ostrikov, "Anti-bacterial surfaces: natural agents, mechanisms of action, and plasma surface modification," Rsc Advances, vol. 5, no. 60, pp. 48739-48759, 2015.

[5] Y.-T. Tung, P.-L. Yen, C.-Y. Lin, and S.-T. Chang, "Antiinflammatory activities of essential oils and their constituents from different provenances of indigenous cinnamon (Cinnamomum osmophloeum) leaves," Pharmaceutical Biology, vol. 48, no. 10, pp. 1130-1136, 2010.

[6] S. D. Cox, C. M. Mann, J. L. Markham et al., "The mode of antimicrobial action of the essential oil of Melaleuca alternifolia (tea tree oil)," Journal of Applied Microbiology, vol. 88, no. 1, pp. 170-175, 2000.

[7] I. Čabarkapa, R. Čolović, D. J. Olivera et al., "Anti-biofilm activities of essential oils rich in carvacrol and thymol against Salmonella enteritidis," Biofouling, vol. 35, no. 3, pp. 361-375, 2019.
[8] E. N. Gasu, H. Senanu Ahor, and L. Sheringham Borquaye, "Peptide mix from olivancillaria hiatula interferes with cellto-cell communication in Pseudomonas aeruginosa," BioMed Research International, vol. 2019, Article ID 5313918, 12 pages, 2019.

[9] F. Shahidi, "Antioxidants in food and food antioxidants," Nahrung/Food, vol. 44, no. 3, pp. 158-163, 2000.

[10] J. Gómez-Estaca, C. López-de-Dicastillo, P. HernándezMuñoz, R. Catalá, and R. Gavara, "Advances in antioxidant active food packaging," Trends in Food Science \& Technology, vol. 35, no. 1, pp. 42-51, 2014.

[11] J. N. Gyesi, R. Opoku, and L. S. Borquaye, "Chemical composition, total phenolic content, and antioxidant activities of the essential oils of the leaves and fruit pulp of Annona muricata L. (Soursop) from Ghana," Biochemistry Research International, vol. 2019, Article ID 4164576, 9 pages, 2019.

[12] S. O. Bada, "Preliminary information on the ecology of Chrysophyllum albidum G. don in West and Central Africa," in Proceedings of National Workshop on the Potentials of Star Apple in Nigeria, vol. 16-25, Ibadan, Nigeria, 1997.

[13] H. O. Ibrahim, O. Osilesi, O. O. Adebawo, F. D. Onajobi, L. B. Muhammad, and K. O. Karigidi, "In vitro assessment of the potential antioxidant and antidiabetic properties of edible parts of Chrysophyllum albidum fruit extracts," Journal of Food and Nutrition Research, vol. 7, no. 2, pp. 105-113, 2019.

[14] O. P. Duyilemi and I. O. Lawal, "Antibacterial activity and phytochemical screening of Chrysophyllum albidum leaves," Asian Journal of Food and Agro-Industry, vol. 2, 2009.

[15] G. L. Arueya, G. F. Ugwu, and G. Febechi Ugwu, "Development and evaluation of african star apple (Chrysophyllum albidum) based food supplement and its potential in combating oxidative stress," Journal of Functional Foods, vol. 33, pp. 376-385, 2017.

[16] H. O. Ibrahim, O. Osilesi, O. O. Adebawo, F. D. Onajobi, K. O. Karigidi, and L. B. Muhammad, "Nutrients compositions and phytochemical contents of edible parts of Chrysophyllum albidum fruit," Journal of Nutrition \& Food Sciences, vol. 7, no. 2, pp. 1-9, 2017.

[17] O. Lasekan, A. Khatib, H. Juhari, P. Patiram, and S. Lasekan, "Headspace solid-phase microextraction gas chromatography-mass spectrometry determination of volatile compounds in different varieties of African star apple fruit (Chrysophillum albidum)," Food Chemistry, vol. 141, no. 3, pp. 2089-2097, 2013.

[18] F. Ishola, S. Aboaba, M. Iqbal Choudhary, and O. Ekundayo, "Chemical and biological assessments of the essential oils of Chrysophyllum albidum G. don," Journal of Agricultural Science and Technology A, vol. 7, 2017.

[19] V. I. Babushok, "Chromatographic retention indices in identification of chemical compounds," TrAC Trends in Analytical Chemistry, vol. 69, pp. 98-104, 2015.

[20] L. S. Borquaye, E. Ocansey, and J. Semenya, "Inhibitory effect of selected Ghanaian clay leachates on some pathogenic microbes," American Journal of Microbiology and Immunology, vol. 1, no. 1, pp. 1-5, 2016.

[21] E. N. Gasu, H. Senanu Ahor, and L. Sheringham Borquaye, "Peptide extract from Olivancillaria hiatula exhibits broadspectrum antibacterial activity," BioMed Research International, vol. 201811 pages, 2018.

[22] G. Afu, M. K. Laryea, and L. Sheringham Borquaye, "Biological efficacy and toxicological evaluation of ethanolic extract of Cassia nodosa buch.-ham.(leguminosae)," Journal of Chemistry, vol. 202013 pages, 2020. 
[23] L. S. Borquaye, M. K. Laryea, E. N. Gasu et al., "Anti-inflammatory and antioxidant activities of extracts of Reissantia indica, Cissus cornifolia and Grosseria vignei," Cogent Biology, vol. 6, no. 1, Article ID 1785755, 2020.

[24] H. J. Damien Dorman, S. G. Deans, R. C. Noble, and P. Surai, "Evaluation in vitro of plant essential oils as natural antioxidants," Journal of Essential Oil Research, vol. 7, no. 6, pp. 645-651, 1995.

[25] D. Mottram, "The LRI and Odour Database," 2021, http:// www.odour.org.uk/.

[26] A. E. Yñigez-Gutierrez and B. O. Bachmann, "Fixing the unfixable: the art of optimizing natural products for human medicine," Journal of Medicinal Chemistry, vol. 62, no. 18, pp. 8412-8428, 2019.

[27] J. Sharifi-Rad, A. Sureda, G. Tenore et al., "Biological activities of essential oils: from plant chemoecology to traditional healing systems," Molecules, vol. 22, no. 1, p. 70, 2017.

[28] C. Sell, "Chemistry of essential oils," in Handbook of Essential Oils, Science, Technology, and Applications, K. Hüsnü Can Baser and G. Buchbauer, Eds., pp. 121-150, CRC Press, Boca Raton, FL, USA, 1st edition, 2010.

[29] M. T. Baratta, H. J. D. Dorman, S. G. Deans, D. M. Biondi, and G. Ruberto, "Chemical composition, antimicrobial and antioxidative activity of laurel, sage, rosemary, oregano and coriander essential oils," Journal of Essential Oil Research, vol. 10, no. 6, pp. 618-627, 1998.

[30] I. Lara, R. M. Miró, T. Fuentes, G. Sayez, J. Graell, and M. L. López, "Biosynthesis of volatile aroma compounds in pear fruit stored under long-term controlled-atmosphere conditions," Postharvest Biology and Technology, vol. 29, no. 1, pp. 29-39, 2003.

[31] Wannes, W. Aidi, B. Mhamdi, and B. Marzouk, "Variations in essential oil and fatty acid composition during Myrtus communis var. Italica fruit maturation," Food Chemistry, vol. 112, no. 3, pp. 621-626, 2009.

[32] P. C. Santos-Gomes and M. Fernandes-Ferreira, "Organ-and season-dependent variation in the essential oil composition of Salvia officinalis L. cultivated at two different sites," Journal of Agricultural and Food Chemistry, vol. 49, no. 6, pp. 29082916, 2001.

[33] K. K. Kuorwel, M. J. Cran, K. Sonneveld, J. Miltz, and S. W. Bigger, "Essential oils and their principal constituents as antimicrobial agents for synthetic packaging films," Journal of Food Science, vol. 76, no. 9, pp. R164-R177, 2011.

[34] S.-K. Yang, K. Yusoff, M. Ajat, W.-S. Yap, and K.-S. Lai, "Antimicrobial activity and mode of action of terpene linalyl anthranilate against carbapenemase-producing Klebsiella pneumoniae," Journal of Pharmaceutical Analysis, vol. 11, no. 2, pp. 210-219, 2020.

[35] M. Simões, S. . Rocha, M. A. Coimbra, and M. J. Vieira, "Enhancement of Escherichia coli and Staphylococcus aureus antibiotic susceptibility using sesquiterpenoids," Medicinal Chemistry, vol. 4, no. 6, pp. 616-623, 2008.

[36] R. Roy, M. Tiwari, G. Donelli, and V. Tiwari, "Strategies for combating bacterial biofilms: a focus on anti-biofilm agents and their mechanisms of action," Virulence, vol. 9, no. 1, pp. 522-554, 2018.

[37] J. Kiplimo, N. Koorbanally, and H. Chenia, “Triterpenoids from vernonia auriculifera hiern exhibit antimicrobial activity," African Journal of Pharmacy and Pharmacology, vol. 5, no. 8, pp. 1150-1156, 2011.

[38] S. Purkait, A. Bhattacharya, A. Bag, and R. R. Chattopadhyay, "Evaluation of antibiofilm efficacy of essential oil components B-caryophyllene, cinnamaldehyde and eugenol alone and in combination against biofilm formation and preformed biofilms of Listeria monocytogenes and Salmonella typhimurium," Letters in Applied Microbiology, vol. 71, no. 2, pp. 195-202, 2020.

[39] E.-B. Kerekes, É. Deák, M. Takó et al., “Anti-biofilm forming and anti-quorum sensing activity of selected essential oils and their main components on food-related micro-organisms," Journal of Applied Microbiology, vol. 115, no. 4, pp. 933-942, 2013.

[40] K. V. Ramana, S. Srivastava, and S. S. Singhal, "Lipid peroxidation products in human health and disease 2016," Oxidative Medicine and Cellular Longevity, vol. 2017, Article ID 2163285, 2 pages, 2017.

[41] R. Amorati, M. C. Foti, and L. Valgimigli, "Antioxidant activity of essential oils," Journal of Agricultural and Food Chemistry, vol. 61, no. 46, pp. 10835-10847, 2013. 